\title{
Exploring reasons for non-vaccination against human papillomavirus in Italy
}

\author{
Cristina Giambi ${ }^{1,2^{*}}$, Fortunato D'Ancona ${ }^{1}$, Martina Del Manso ${ }^{1}$, Barbara De Mei ${ }^{3}$, llaria Giovannelli ${ }^{3}$, \\ Chiara Cattaneo ${ }^{3}$, Valentina Possenti ${ }^{3}$, Silvia Declich ${ }^{1}$ and Local Representatives for VALORE
}

\begin{abstract}
Background: In Italy, free-of-charge HPV vaccination is offered to 11-year-old girls since 2007. The National Immunization Plan established the target coverage at a minimum of 70\%; it should increase to 95\% within 3-year time frame. In 2012, four year after the introduction of HPV vaccination, coverage was stable at 69\%. We conducted a national cross-sectional study to explore barriers to vaccination in Italy.
\end{abstract}

Methods: Vaccination services selected, through the immunization registries, a sample of unvaccinated girls born in 1997 or 1998 and posted to their families a 23-items questionnaire inquiring barriers to vaccination, HPV knowledge, source of information on HPV, perception of risk of contracting HPV, advice from consulted health professionals on HPV vaccination.

Results: We analysed 1,738 questionnaires. Main barriers were fear of adverse events (reported by $80 \%$ of families), lack of trust in a new vaccine (76\%), discordant information received by health professionals (65\%) and scarce information on HPV vaccination (54\%). Overall, 54\% of families replied correctly to more than half of 10 questions exploring knowledge on HPV vaccination. Families with a high knowledge score were more likely to live in Northern and Central Italy, be Italian, have a high educational level, include a mother who attended cervical screening regularly and consult more information sources. Although paediatricians/general practitioners and gynaecologists were considered the most trusted source of information by $79 \%$ and $61 \%$ of respondents, they were consulted only by $49 \%$ and 31\%. Among parents who discussed vaccination with a physician, 28\% received discordant advices and 31\% received the recommendation of accepting vaccination.

Conclusions: Fear of adverse events, discordance of information and advices from physicians, and scarce information were the more commonly reported barriers to HPV vaccination. Health professionals played a key role as information providers, thus they must be better trained to provide clear notions. Training needs to include the development of communication skills; transparent discussion about the pros and cons of vaccination may reduce fear of adverse events and increase trust in vaccination. The creation of a public health network around vaccination would allow sharing information and attitudes on vaccinations, so that homogeneous messages could reach the target population.

Keywords: Human papillomavirus infection, Vaccines and immunisation, Uterine cervical cancer, Immunisation programs, Reasons for non-vaccination, Acceptance

\footnotetext{
* Correspondence: cristina.giambi@iss.it

${ }^{1}$ Communicable Disease Epidemiology Unit; National Centre for

Epidemiology, Surveillance and Health Promotion; Istituto Superiore di

Sanità, Viale Regina Elena 299; 00161, Rome, Italy

European Programme for Intervention Epidemiology Training (EPIET),

European Centre for Disease Prevention and Control, Stockholm, Sweden

Full list of author information is available at the end of the article
} 


\section{Background}

Human Papillomavirus (HPV) vaccination represents an important opportunity for primary prevention of cervical cancer (CC). HPV vaccines have a high efficacy against cervical pre-cancer lesions if given to females before they are exposed to the virus [1], therefore the World Health Organization (WHO) recommends to offer HPV vaccination to pre-teen girls.

As of December 2012, 22 of 31 EU/EEA countries had implemented HPV vaccination. Target age, financing and vaccine delivery differ among countries [2]. In 2012, European countries report coverage varying from $17 \%$ to $84 \%$ [3].

In Italy, since 2007, public immunization services of all Local Health Units (LHUs) actively invite 11-year-old girls for free-of-charge HPV vaccination [4]; most LHUs plan one or more reminders for non-respondents. In spring 2007 the Italian Ministry of Health started a nationwide information campaign; most regions also conducted additional campaigns. The 2012-2014 National Immunization Plan established the target coverage rate at a minimum of $70 \%$ of 11 year-old girls vaccinated with three doses of HPV vaccine; it should increase to $95 \%$ within 3-year time frame [5]. On 30/06/2013, 4 years after the introduction of HPV vaccination, the national immunization coverage of the first cohorts called for vaccination (1997-1999) was stable at 69\% [6]. Adolescents represent a difficult target for vaccination; an Italian survey carried out in 2008 found that only 53\% of 15-year-old adolescents had received the diphtheria-tetanus booster dose planned at 11-15 years [7].

Many studies explored factors influencing HPV vaccination uptake and parental attitudes towards HPV vaccination. Three 2012-13 reviews [8-10] indicated that (a) recommendation from a doctor is the main driver of vaccination, (b) safety is a key parental concern, (c) HPV vaccine-related knowledge is positively associated with vaccination uptake and (d) school-based immunization programs increase vaccination coverage.

In Italy no research on barriers to HPV vaccination targeting parents of unvaccinated girls was available at national level. We conducted a survey among a sample of families of unvaccinated girls to explore reasons for non-vaccination. Understanding parental reasons for not vaccinating their daughters can help public health authorities to implement interventions increasing HPV vaccine acceptance.

\section{Methods}

\section{Study design}

We conducted a cross-sectional study in the period November 2011-July 2012 as part of a national project (VALORE), coordinated by the National Institute of Public Health (Istituto Superiore di Sanità, ISS) and funded by the Ministry of Health.
The survey addressed families of unvaccinated girls born in 1997 or 1998 who were offered vaccination in 2008-2010. We invited all 143 LHUs to participate (distributed in 21 regions/autonomous provinces). We excluded LHUs that were implementing an HPV vaccine catch-up programme targeting birth cohorts 1997 or 1998 at the time of the study.

LHUs identified unvaccinated girls through the immunization registries. For calculating the sample size we assumed a precision of $10 \%$, an alpha error of $5 \%$ and, given that current reference literature data was not available, a prevalence of $50 \%$. According to these parameters, we needed a sample of at least 96 units for each LHU/region to provide sufficient power to generate estimates at local/regional level. Assuming a response of $30 \%$, we randomly selected 320 girls from each list of unvaccinated girls. If unvaccinated girls were fewer than 320, we invited all of them.

\section{The questionnaire}

We developed a 23-item questionnaire (mainly close-ended, 15 minutes needed for administration) inquiring about: 1) demographic information, 2) vaccination status, 3) barriers/ reasons for non-vaccination, 4) HPV knowledge, 5) source of information on HPV, 6) perception of risk that their daughter could contract HPV, 7) intention to have their daughter vaccinated in the future, 8) advice from consulted health care workers (HCWs) on HPV vaccination, 9) parents' socio-demographic and behavioural characteristics. Copies of the questionnaire (in Italian) are available from the authors.

To investigate barriers to vaccination, we proposed a list of 23 possible reasons for non-vaccination and asked participants to indicate how much each factor had influenced their decision of non-vaccination on a 4-point scale (A lot/sufficiently/a little/not at all). To explore HPV knowledge, we proposed ten statements on HPV infection/vaccination, with three options available (True/ False/Do not know). Regarding sources of information, we proposed a list and asked participants who provided them information (they could indicate more than one source) and which sources they considered more trusted (they could indicate a maximum of three sources). For the other questions, answers with multiple options were proposed and parents could indicate one.

We administered the questionnaire to a convenience sample of parents to ensure clarity and ease of administration, collected their comments and modified accordingly.

\section{Data collection}

In the period January-March 2012, vaccination services posted to the selected families a letter explaining the purpose of the study, the self-administered questionnaire, a stamp-addressed reply envelope to return the questionnaire 
to ISS and the invitation to the immunization service to get free-of-charge HPV vaccination. Since the survey was voluntary and anonymous, completing the questionnaire was considered as consent to participate. The national ethics committee of the ISS approved the study protocol.

\section{Statistical analysis}

We summarized categorical variables using frequencies and proportions and used Chi-square test, Fisher's exact test and Chi-square for trend to compare proportions. We defined statistical significance as a 2-tailed $p$-value of $<0.05$. For the purpose of the uni-variate and multivariable analysis, we dichotomized the following variables: educational level (at least one parent with high school or college degree/other), age (at least one parent $<45$ years/ other), occupation (at least one employed parent/other), mother's attitude toward Pap test (regularly undergone/ done once or never) and other accepted paediatric vaccinations (all proposed vaccinations/only some vaccinations or none). We computed a dichotomized knowledge score based on the number of correct answers on HPV infection and vaccination $(\leq 5 />5)$ (outcome). We calculated odds ratios and their $95 \%$ confidence intervals (95\% CI) to assess the association between selected variables and the outcome (knowledge score). We included into a logistic regression model the variables showing potentially interesting associations with the outcome and we used a forward stepwise procedure with the method of the likelihood ratio test for goodness-of-fit in order to control for possible confounding factors. At each step, a p-value of 0.10 was used as entry criterion and a v value of 0.15 as removal criterion. We used the statistical package STATA 11.2 to analyse data (Stata Corporation, College Station, Texas, USA).

\section{Results}

\section{Study participation}

Fifty-six LHUs in ten regions participated in the survey: 32 in the North, 16 in the Centre and 8 in the South. Vaccination services posted 14,099 letters and 2,110 questionnaires returned to ISS, with a response of $15 \%$ (16.5\% in the North, $12.2 \%$ in the Centre and $10.3 \%$ in the South). We excluded 372 questionnaires: 25 were filled incorrectly, 57 were sent to wrong cohorts and 290 to girls already vaccinated against HPV. Overall, we analysed 1,738 questionnaires.

The number of letters returned to the sender because of unknown recipient was available for 39/56 LHUs; $7.3 \%$ of letters $(816 / 11,187)$ returned to the vaccination centre, with a wide range among LHUs (0-22\%).

\section{Study population}

Ninety-nine percent of girls were Italian; 80\% lived in the North of Italy; $99 \%$ had received other paediatric vaccinations. In most cases (74\%) the mother filled the questionnaire; $81 \%$ of girls had at least one parent with secondary school or university degree; $88 \%$ of mothers underwent Pap-test regularly (Table 1). Before the invitation to this project, $7 \%$ of families had not received any call for $\mathrm{HPV}$ vaccination from immunization services.

\section{Barriers to HPV vaccination}

The main reasons that influenced a lot/sufficiently the decision not to accept HPV vaccination were fear of adverse events (reported by $80 \%$ of families, 95\% CI 78.4-82.3), lack of trust in a new vaccine (76\%, 95\% CI 74.7-78.8), discordance of information received by HCWs on HPV vaccination (65\%, 95\% CI 62.6-67.4) and scarce information on HPV vaccination (54\%, 95\% CI 51.8-56.7) (Figure 1). These four factors represented the main barriers to vaccination, also when stratifying by area and educational level.

A negative advice concerning HPV vaccination from the family doctor or other health professionals was indicated by $24 \%$ (95\% CI 21.5-23.6) and 28\% (95\% CI 25.8$28.5)$ of parents; combining these two questions, $39 \%$ (95\% CI 36.9-41.7) of families reported that a negative advice from a physician influenced the decision of nonvaccination. The belief that the age for vaccination was too young was reported by $45 \%$ (95\% CI 43.1-48.1). Only $16 \%$ (95\% CI 14.4-18.1) feared that vaccination would encourage more risky sexual activity. Issues linked to the access to vaccination services influenced marginally the acceptance (Figure 1).

Out of 1,708 families, 827 (49\%) confirmed the intention to refuse HPV vaccination for their daughter in the future, 504 (29\%) had not taken a decision yet and 377 (22\%) intended to accept vaccination.

\section{Knowledge on HPV infection and vaccination}

Most respondents were aware of the causal relationship between HPV and CC (93\%), the high frequency of HPV infections (70\%), the sexual transmission of HPV (77\%) and its asymptomatic nature (72\%). Few respondents were aware of the transient nature of most HPV infections (19\%), the possibility for men to be infected (37\%) and the connection between HPV and genital warts (29\%) (Table 2). Each family replied correctly to a mean of 5.6/10 questions. Compared with others, families with a high knowledge score were more likely to live in Northern and Central Italy, be Italian, have a high educational level, include a mother who attended cervical screening regularly and consult more information sources (Table 3).

Out of 1664 families, 561 (34\%) considered their daughter at risk of contracting HPV, 226 (14\%) did not perceive any risk and 877 (53\%) were not able to reply. The proportion of families perceiving the risk increased from $9.1 \%$ among those families that gave one correct 
Table 1 Characteristics of the study population; Italy, 2012

\begin{tabular}{|c|c|c|c|}
\hline & & $\mathrm{n}$ & $\%$ \\
\hline \multirow[t]{2}{*}{ Birth Cohort $(N=1738)$} & 1997 & 167 & 9.6 \\
\hline & 1998 & 1571 & 90.4 \\
\hline \multirow{3}{*}{$\begin{array}{l}\text { Geographic area } \\
(N=1729)\end{array}$} & North & 1390 & 80.4 \\
\hline & Centre & 207 & 12.0 \\
\hline & South & 132 & 7.6 \\
\hline \multirow[t]{2}{*}{ Nationality ( $N=1726)$} & Italian & 1659 & 96.1 \\
\hline & Foreign & 67 & 3.9 \\
\hline \multirow[t]{3}{*}{$\begin{array}{l}\text { Other paediatric } \\
\text { vaccinations }(\mathrm{N}=1715)\end{array}$} & $\begin{array}{l}\text { Yes, all proposed by } \\
\text { paediatrician/vaccination service }\end{array}$ & 1393 & 81.2 \\
\hline & Yes, some of them & 304 & 17.7 \\
\hline & No & 18 & 1.04 \\
\hline \multirow{4}{*}{$\begin{array}{l}\text { MMR vaccination } \\
(N=1692)\end{array}$} & 1 dose & 332 & 19.6 \\
\hline & 2 doses & 1124 & 66.4 \\
\hline & No MPR vaccination & 191 & 11.3 \\
\hline & I do not remember & 45 & 2.7 \\
\hline \multirow{4}{*}{$\begin{array}{l}\text { Parents' nationality } \\
(N=1705)\end{array}$} & Both Italian & 1516 & 88.9 \\
\hline & Both foreign & 62 & 3.6 \\
\hline & Italian/Foreign & 30 & 1,8 \\
\hline & Other & 97 & 5.7 \\
\hline \multirow[t]{4}{*}{ Parents' age $(N=1712)$} & $<45$ years, both parents & 498 & 29.1 \\
\hline & $\geq 45$ years, both parents & 727 & 42.5 \\
\hline & $<45 / \geq 45$ & 397 & 23.2 \\
\hline & Other & 90 & 5.3 \\
\hline \multirow[t]{4}{*}{$\begin{array}{l}\text { Parents' education level } \\
(N=1717)\end{array}$} & $\begin{array}{l}\text { High school or college degree, } \\
\text { both parents }\end{array}$ & 879 & 51.2 \\
\hline & $\begin{array}{l}\text { High school or college/primary } \\
\text { or middle school degree }\end{array}$ & 452 & 26.3 \\
\hline & $\begin{array}{l}\text { Primary or middle school } \\
\text { degree, both parents }\end{array}$ & 290 & 16.9 \\
\hline & Other & 96 & 5.6 \\
\hline \multirow{4}{*}{$\begin{array}{l}\text { Parents' status of } \\
\text { employment }(N=1663)\end{array}$} & Both parents employed & 1111 & 66.8 \\
\hline & Only one parent employed & 499 & 30.0 \\
\hline & Both parents unemployed & 17 & 1,0 \\
\hline & Other & 36 & 2.2 \\
\hline \multirow{2}{*}{$\begin{array}{l}\text { Adolescents ( }>16 \text { years) in } \\
\text { the family }(N=1714)\end{array}$} & $\geq 1$ & 642 & 37.5 \\
\hline & 0 & 1072 & 62.5 \\
\hline \multirow[t]{2}{*}{$\begin{array}{l}\text { Parents' smoking habit } \\
(\mathrm{N}=1727)\end{array}$} & $\begin{array}{l}\text { At least } 1 \text { non/ex smoker } \\
\text { parent }\end{array}$ & 1614 & 93.5 \\
\hline & Other & 113 & 6.5 \\
\hline \multirow{3}{*}{$\begin{array}{l}\text { Mother' attitude toward } \\
\text { Pap test }(\mathrm{N}=1673)\end{array}$} & She regularly undergoes & 1469 & 87.8 \\
\hline & She underwent at least once & 160 & 9.5 \\
\hline & Never done & 44 & 2.7 \\
\hline \multirow{3}{*}{$\begin{array}{l}\text { Parent who filled the } \\
\text { questionnaire }(N=1713)\end{array}$} & Mother & 1265 & 73.8 \\
\hline & Father & 76 & 4.4 \\
\hline & Both parents & 372 & 21.7 \\
\hline
\end{tabular}

answer to $59.2 \%$ among those who replied to all questions correctly ( $\mathrm{p}<0.0001$, Chi-square for trend).

\section{Sources of information on HPV infection and vaccination}

Ninety-three parents (5\%) had never heard about HPV. Paediatrician/general practitioner represented the most commonly consulted source of information on HPV vaccination; the most trusted sources of information included paediatrician/general practitioner and gynaecologist. Although $79 \%$ and $61 \%$ of families trusted more their paediatrician/general practitioner and their gynaecologist, only $49 \%$ and $31 \%$ of the respondents had consulted these specialists (Table 4).

Overall, 870 (56\%) families consulted health professionals and other sources of information, while 358 (23\%) had not received information by any physician; 906 (53\%) indicated learning on HPV vaccination from 2-3 sources (Table 4).

Of 1,710 families, 600 (35\%) felt sufficiently informed regarding HPV infection and vaccination; 787 (46\%) did not feel enough informed and 323 (19\%) were not able to give an opinion. Of 1,562 families, the information received by health professionals were considered appropriate to decide on HPV vaccination by 622 (40\%); scarce and generic by 314 (20\%); unclear regarding the vaccine mechanism by 278 (18\%) and unclear on safety issues by $623(40 \%)$.

\section{Health professionals' advice regarding HPV vaccination}

Out of 1,703, 345 (20\%) parents did not discuss about $\mathrm{HPV}$ vaccination with any health professional. Among the 1,358 parents who addressed the issue of HPV vaccination with a physician, 377 (28\%) received discordant advices; only 421 (31\%) parents received the recommendation of accepting HPV vaccination (Figure 2).

\section{Discussion}

In our study, participants: 1) feared the occurrence of adverse events of HPV vaccination, 2) were not well informed and aware of HPV infection and vaccination, 3) had received discordant advices and information on HPV vaccination from health professionals.

Regarding the first point, concern about side effects was the main barrier to acceptance, in accordance with previous surveys [10-12]. The incidence of many vaccinepreventable diseases has decreased, thus the risk of the potential vaccine adverse effects is perceived to be greater than the risk of the disease. The provision of complete information on vaccine safety by well-trained HCWs could encourage acceptance. Pre-vaccination counselling has to cover not only the benefits of vaccination and the risks related to the disease, but also consider doubts, fears, and risk of severe side-effects. To increase trust in vaccination, information needs to be clear, detailed and evidence-based. Communicating that vaccination 


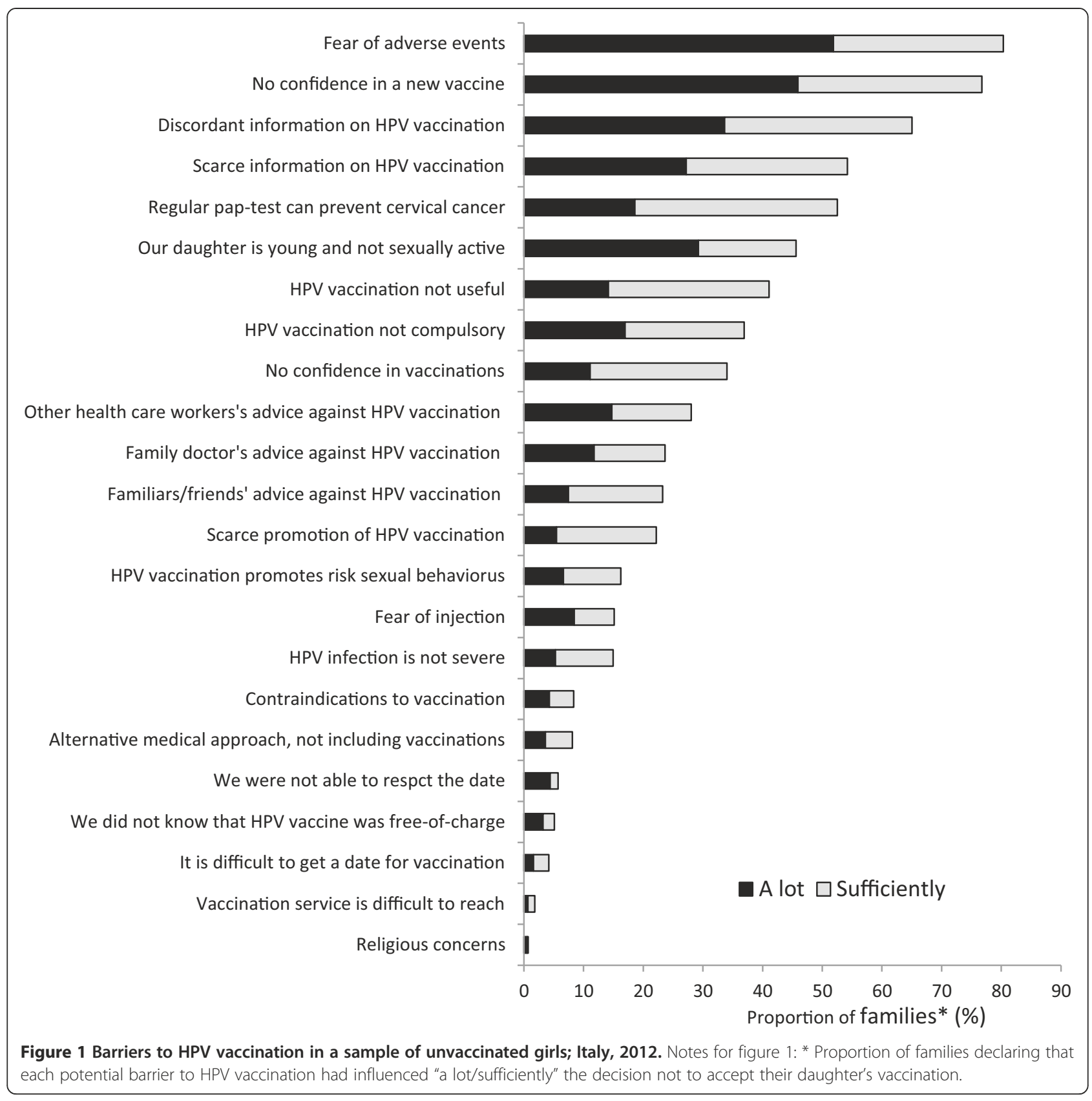

entails no risk may, paradoxically, lead patients to view vaccines as more risky [13].

Concerning the second point, the level of knowledge on HPV infection/vaccination was low. Since responders had received an invitation for their daughter's vaccination, they could have been more likely to seek HPV-related information. However, only $54 \%$ of families replied correctly to more than half questions. Our data suggest that many respondents do not understand the link between HPV and genital warts, the possibility for men to be infected and the transient nature of most HPV infections; other surveys conducted in Italy on the same topic [14-16] confirmed that knowledge on these aspects is not consolidated.

Only one third of families felt enough informed and the same proportion perceived the risk that their daughter could acquire the infection. Although knowledge does not predict behaviour's modification, it is a prerequisite for an aware decisional process on vaccination. A higher vaccine-related knowledge was positively associated with HPV vaccination uptake $[8,9]$ or intention of undergoing HPV vaccination [15]. According to Trim et al. [10], concern about the potential risk of cancer and believing their daughters might contract HPV and related diseases 
Table 2 Parents' knowledge on HPV infection and vaccination; Italy, 2012

\begin{tabular}{lll}
\hline Questions exploring knowledge & n/N & \%* \\
\hline HPV may cause cervical cancer (T) & $1571 / 1690$ & 93.0 \\
HPV is a sexually transmitted disease (T) & $1295 / 1675$ & 77.3 \\
HPV may infect you without symptoms (T) & $1195 / 1669$ & 71.6 \\
HPV infections are rare (F) & $1167 / 1661$ & 70.3 \\
HPV vaccines work well if given before sexual & $1045 / 1655$ & 63.1 \\
debut (T) & & \\
HPV vaccines protect against all HPV types (F) & $981 / 1670$ & 58.7 \\
Sometimes HPV infections can last years (T) & $899 / 1646$ & 54.6 \\
Only women can be infected by HPV (F) & $615 / 1647$ & 37.3 \\
Genital warts are caused by HPV (T) & $471 / 1633$ & 28.8 \\
Most HPV infections resolve spontaneously (T) & $320 / 1662$ & 19.3 \\
\hline
\end{tabular}

*Proportion of parents that replied to each question correctly. The correct answer is indicated among bracket ( $\mathrm{T}=$ true, $\mathrm{F}=$ false). drive HPV vaccination. Also Donati et al. [15] found that women who were fairly and very worried about getting an HPV infection had a higher probability of accepting vaccination.

Regarding the third point, discordant information and advice received by different health professionals hindered vaccination for $65 \%$ of families. Only $31 \%$ received positive advice from a physician. Studies reported that a proportion of clinicians had substantial concerns about promoting vaccination, particularly for younger age groups [17]. National [15,18] and international $[9-11,19,20]$ literature reports that health care provider recommendation is one of the main factors driving acceptance. To guide families towards an informed decision regarding vaccination, physicians need to provide complex explanations (e.g., why the vaccine is offered only to females, why it has to be administered to girls before sexual debut and the fact that the currently available vaccines only prevent certain HPV oncogenic types). Moreover HPV is a sexually transmitted infection and the promotion of programs regarding sexual issues can be more difficult than other

Table 3 Determinants of high score of knowledge on HPV infection and vaccination; Italy, 2012

\begin{tabular}{|c|c|c|c|c|c|c|}
\hline \multirow[t]{2}{*}{ Variables } & & \multirow[b]{2}{*}{ n (\%) } & \multicolumn{2}{|c|}{ Univariate analysis } & \multicolumn{2}{|c|}{ Logistic regression } \\
\hline & & & OR $_{\text {crude }}$ & $95 \% \mathrm{Cl}$ & $\mathrm{OR}_{\mathrm{adj}}$ & $95 \% \mathrm{Cl}$ \\
\hline \multirow[t]{3}{*}{ Geografical area } & North & $747(55.0)$ & 2.06 & $1.42-2.99$ & 1.79 & $1.17-2.75$ \\
\hline & Centre & $115(56.7)$ & 2.20 & $1.40-3.47$ & 1.73 & $1.04-2.89$ \\
\hline & South & $48(37.2)$ & 1 & - & 1 & - \\
\hline \multirow[t]{2}{*}{ Nationality } & Italian & $901(55.4)$ & 4.68 & $2.52-8.69$ & 3.03 & $1.55-5.91$ \\
\hline & Foreign & $13(21.0)$ & 1 & - & 1 & - \\
\hline \multirow[t]{2}{*}{ Other paediatric vaccinations } & All proposed vaccinations & $724(53.0)$ & & & & \\
\hline & Only some vaccinations /None & $186(58.1)$ & & & & \\
\hline \multirow[t]{2}{*}{ Adolescents ( $>16$ years) in the family } & $\geq 1$ & $868(54.8)$ & & & & \\
\hline & 0 & $43(39.1)$ & & & & \\
\hline \multirow[t]{2}{*}{ Parents' education level } & At least 1 parent with high school or college degree & $821(59.7)$ & 3.76 & $2.87-4.92$ & 3.10 & $2.33-4.15$ \\
\hline & Other & $88(28.3)$ & 1 & - & 1 & - \\
\hline \multirow[t]{2}{*}{ Parents' age } & at least 1 parent $<45$ years & $464(50.5)$ & 1.34 & $1.10-1.62$ & & \\
\hline & Other & $440(57.7)$ & 1 & - & & \\
\hline \multirow[t]{2}{*}{ Parents' status of employment } & At least 1 parent employed & $863(54.5)$ & & & & \\
\hline & Other & $22(45.8)$ & & & & \\
\hline \multirow[t]{2}{*}{ Parents' smoking habit } & At least 1 non/ex smoker parent & $808(55.2)$ & 1.89 & $1.27-2.81$ & & \\
\hline & Other & $97(46.0)$ & 1 & - & & \\
\hline \multirow[t]{2}{*}{ Mother' attitude toward Pap test } & Regularly undergone & $849(58.7)$ & 3.99 & $2.86-5.57$ & 2.66 & $1.85-3.84$ \\
\hline & Done once or never & $52(26.3)$ & 1 & - & 1 & \\
\hline \multirow[t]{3}{*}{ Number of source of information } & $0-1$ & $156(33.0)$ & 1 & - & 1 & - \\
\hline & $2-3$ & $525(58.3)$ & 2.84 & $2.25-3.59$ & 2.30 & $1.79-2.96$ \\
\hline & $\geq 4$ & $229(72.9)$ & 5.47 & $4.00-7.49$ & 3.96 & $2.84-5.53$ \\
\hline
\end{tabular}

Determinants of high score of knowledge * on HPV infection and vaccination; Italy, 2012.

*We computed a dichotomized knowledge score based on the number of correct answers on HPV infection and vaccination: "high" if $>5$ correct answers; "low" if $\leq 5$ correct answers 
Table 4 Sources of information on HPV infection and vaccination; Italy, 2012

\begin{tabular}{|c|c|c|c|}
\hline & & $\mathrm{n}$ & $\%$ \\
\hline \multirow[t]{11}{*}{$\begin{array}{l}\text { Used sources of information } \\
(\mathrm{N}=1616 \wedge)\end{array}$} & $\begin{array}{l}\text { Paediatrician/general } \\
\text { practitioner }\end{array}$ & 794 & 49.1 \\
\hline & Friends/family members & 651 & 40.3 \\
\hline & Internet & 553 & 34.2 \\
\hline & Gynaecologist & 495 & 30.6 \\
\hline & $\begin{array}{l}\text { Newspaper/leaflet/ } \\
\text { poster }\end{array}$ & 434 & 26.9 \\
\hline & Vaccination services & 403 & 24.9 \\
\hline & Radio/television & 326 & 20.2 \\
\hline & School & 150 & 9.3 \\
\hline & $\begin{array}{l}\text { Mother and child } \\
\text { health centers }\end{array}$ & 93 & 5.8 \\
\hline & Pharmacist & 39 & 2.4 \\
\hline & Other & 109 & 6.7 \\
\hline \multirow[t]{3}{*}{$\begin{array}{l}\text { Mutually exclusive sources } \\
(\mathrm{N}=1565)\end{array}$} & $\begin{array}{l}\text { Health care workers plus } \\
\text { others }\end{array}$ & 870 & 55.6 \\
\hline & $\begin{array}{l}\text { Health care workers } \\
\text { only* }\end{array}$ & 337 & 21.5 \\
\hline & Other sources only** & 358 & 22.9 \\
\hline \multirow{3}{*}{$\begin{array}{l}\text { Number of sources of } \\
\text { information }(N=1565)\end{array}$} & $0-1$ & 486 & 28.4 \\
\hline & $2-3$ & 906 & 53.0 \\
\hline & $\geq 4$ & 317 & 18.6 \\
\hline \multirow[t]{8}{*}{$\begin{array}{l}\text { Most trusted sources of } \\
\text { information }(N=1640)\end{array}$} & $\begin{array}{l}\text { Paediatrician/general } \\
\text { practitioner }\end{array}$ & 1288 & 78.5 \\
\hline & Gynaecologist & 1004 & 61.2 \\
\hline & Vaccination services & 564 & 34.4 \\
\hline & Internet & 342 & 20.9 \\
\hline & $\begin{array}{l}\text { Mother and child } \\
\text { health centers }\end{array}$ & 245 & 14.9 \\
\hline & Friends/family members & 67 & 4.1 \\
\hline & Pharmacist & 36 & 2.2 \\
\hline & Other & 142 & 8.7 \\
\hline
\end{tabular}

$\wedge$ Parents that had never heard about HPV were excluded from the denominator

*gynaecologist, paediatrician/general practiotioner, vaccination service, mother and child health centres, pharmacist

**friends/family members, Internet, newspaper/leaflet/poster

radio/television, school

public health actions, above all if targeting pre-adolescent girls, mostly not sexually active.

In our study, family doctors and gynaecologists were considered the most trusted sources of information. However, there was a discrepancy between consulted and preferred sources of information on HPV vaccination: 30\% of families that considered them as the most trusted source of information did not receive information on HPV from these professionals. A similar discrepancy emerged from a knowledge-attitude-practice survey among young adult Italian women [15]. Since parents preferred paediatricians,

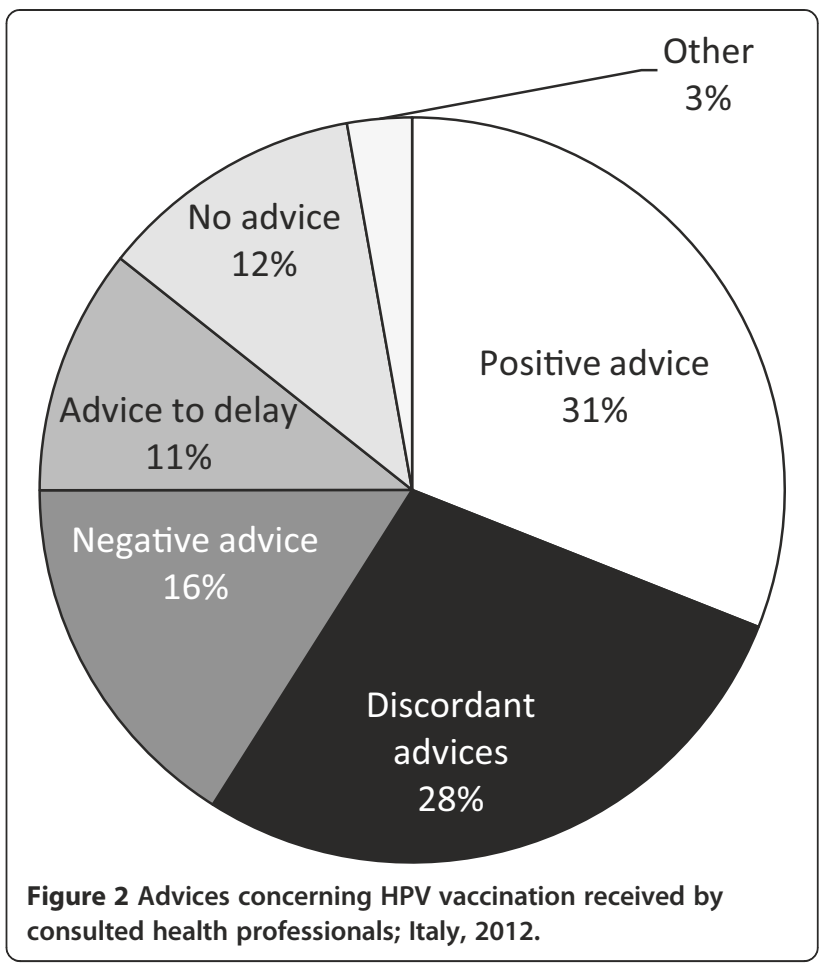

general practitioners and gynaecologists as sources of information, an active offer of information from these specialists at every contact with parents and girls could guide a conscious decision on HPV vaccination.

Only $25 \%$ of families got information on HPV vaccination from immunization services providers and 34\% mentioned them among the most trusted sources of information. Another Italian survey reported that only 12\% of young adult women would have liked to receive information on HPV vaccination by physicians working in vaccination service [15]. Even though vaccinations are offered and administered in public vaccination clinics in Italy, population do not consider immunization services providers as a reference point for vaccination.

HCWs represented the most used source to get information on HPV, but $56 \%$ of parents actively searched other sources and $23 \%$ of families did not consult any health professional and obtained information from alternative sources only. Overall, $34 \%$ of families used the Internet to obtain information on HPV. The vaccine criticism movement took advantage of the Internet's ability to reach parents [21]. A 2012 systematic review of Italian Internet pages on vaccination risks [22] reported that $67 \%$ of 144 pages analysed, often on top positions, was against vaccinations and $24 \%$ of them were written by physicians. All institutional pages (12\%) were pro-vaccinations but they did not score high in visibility. Therefore, a more active presence of health institutions on Internet could "contrast" positions against vaccination, providing reliable and clear information to health professionals and population. 
Caution should be exercised when comparing our results to other studies exploring knowledge on HPV vaccination because of different methodologies and target population. Contrarily to ours, a survey on this topic conducted by Censis [14], an Italian social study and research institute, that involved 3500 women aged 18-55 years, found that mass media are the largest source of information on HPV vaccination. The same finding came out from another national survey carried out on a sample of 667 women aged 18-26 years [15]. A possible explanation of the discordance with our results is that our sample is represented by families that have received an invitation for their daughters to be immunised against HPV and, therefore, they could have been more likely to consult health professionals to get a decision. A survey conducted in Italy among 987 young women supports this finding [23]; the authors found that magazines/books and television represent the main source of information for the over-18 s; instead the under-18 s are mostly informed by HCWs (general practitioners and paediatricians), probably because the under- $18 \mathrm{~s}$ are guided by parents and are therefore accompanied to healthcare services.

Finally, we realized that invitation for HPV vaccination from LHUs did not reach some adolescents. In fact, 7\% of families had not received the active call for HPV vaccination and $7 \%$ of our letters returned to the sender. This suggests that data from the immunization archives could be outdated. The improvement of computerized immunization registries linked to resident/health lists, as addressed in the National immunization Plan [5], represents a priority that will improve the active call of immunization target population and coverage assessment.

The limitations of our study include: scarce geographic representativeness of the sample (most families lived in Northern Italy), lack of a comparative group of parents of vaccinated girls and low response (15\%). The low response might have introduced selection bias; respondents may not represent all unvaccinated girls' families (socio-demographic information of non-respondents are unknown). Because of the low response, the minimum sample size was achieved only in few LHUs; as a result, data could only be analysed at the national level. Previous experiences suggested that posting a self-administered questionnaire could lead to a lower response than face-to-face interviews. However, self-administration represented the easiest procedure to propose participation at the national level without overloading vaccination services.

\section{Conclusions}

Fear of adverse events, discordant information received by $\mathrm{HCWs}$, and scarce information were the more commonly reported barriers to HPV vaccination. It suggests that, in our study, the decision of non-vaccination might come from lack or discordant information on HPV vaccination rather than from a conscious intention to decline vaccination. As HCWs played such a key role as information providers, they must be better trained to provide clear and homogeneous information to adolescents and their parents. Such training should include the development of communication skills; openness and transparent discussion about the pros and cons of HPV vaccination as well the use of appropriate communication strategies may help reducing fear of adverse events and increasing trust in vaccination among parents. Efforts are also needed to stimulate collaboration among health professionals; the creation of a public health network around vaccination would allow sharing information and attitudes on vaccinations, so that homogeneous messages could reach the target population. Such network would enforce the role of public vaccination clinics as reference point for HCWs and general population and encourage an active role of general practitioners, paediatricians and gynaecologists for vaccination promotion. Finally, offering to adolescents a "package of vaccinations" (including HPV, diphtheriatetanus-pertussis, meningococcal, rubella, measles and varicella vaccination, if susceptible) and using all access points in the health system to verify their coverage and offer lacking vaccines could represent an integrated method to increase acceptance among adolescents.

\section{Competing interests}

The authors declare that they have no competing interest.

\section{Authors' contributions}

CG designed the study, prepared the material, coordinated and monitored the study activities, analyzed the data, interpreted the results, drafted and edited the manuscript. FD designed the study, prepared the material, interpreted the results and critically revised the manuscript. MD prepared the material, coordinated the activities of the Local Health Units, analyzed the data and critically revised the manuscript. $B D, I G, C C$ and VP revised the material used for the study and critically revised the manuscript. SD coordinated and monitored the study activities and critically revised the manuscript. Local representatives for VALORE revised the material used for the study, collected data, coordinated the activities in their Local Health Units and critically revised the manuscript. All authors read and approved the final manuscript.

\section{Authors' information}

Multiple affiliations of local representatives for VALORE listed at: http://www.epicentro.iss.it/problemi/hpv/pdf/Allegato3_Gruppo\%20Lavoro\% 20VALORE.pdf.

\section{Acknowledgments}

We wish to thank: Yvan Hutin and loannis Karagiannis, as EPIET programme coordinators, who contributed to the draft and revision of the manuscript; Massimo Fabiani and Antonino Bella for the support to the statistical analysis; Vanessa Cozza who contributed in the preparation of the questionnaire used for data collection.

A special thanks to all of the unvaccinated girls and their families whose participation was essential to achieving the VALORE results.

\section{Funding}

The study and the dissemination of the results were funded by the Italian Ministry of Health - CCM. 


\section{Author details}

${ }^{1}$ Communicable Disease Epidemiology Unit; National Centre for Epidemiology, Surveillance and Health Promotion; Istituto Superiore di Sanità, Viale Regina Elena 299; 00161, Rome, Italy. ²European Programme for Intervention Epidemiology Training (EPIET), European Centre for Disease Prevention and Control, Stockholm, Sweden. ${ }^{3}$ Unit of Training and Communication; National Centre for Epidemiology, Surveillance and Health Promotion; Istituto Superiore di Sanità, Viale Regina Elena 299; 00161, Rome, Italy

Received: 10 March 2014 Accepted: 6 October 2014

Published online: 11 November 2014

\section{References}

1. World Health Organization position paper: Human papillomavirus vaccines. Weekly epidemiological record. 2009, 15(84):117-132. Available at: http://www.who.int/wer/2009/wer8415.pdf Accessed 10 March 2014.

2. European Centre for Disease Prevention and Control: Vaccine schedule. Available at: http://vaccine-schedule.ecdc.europa.eu/Pages/Scheduler.aspx Accessed 10 March 2014

3. European Centre for Disease Prevention and Control: Introduction of HPV vaccines in EU countries - an update. Stockholm: ECDC; 2012. Available at: http://ecdc.europa.eu/en/publications/publications/20120905_gui_hpv_ vaccine update.pdf Accessed 10 March 2014.

4. Presidency of the Council: State-Regions Agreement "Strategies for HPV vaccination active offer in Italy"; 2007. [in Italian] Available at: http://www. statoregioni.it/Documenti/DOC_016696_264\%20csr.pdf Accessed 10 March 2014.

5. Presidency of the Council: State-Regions Agreement "National Immunization Plan 2012-2014 (Piano Nazionale Prevenzione Vaccinale, PNPV)". [in Italian] Available at: http://www.statoregioni.it/Documenti/DOC_035260_54\%20csr \%20punto\%204.pdf Accessed 10 March 2014.

6. Giambi C: CNESPS, Istituto Superiore di Sanità. Progresses of HPV vaccination campaign: vaccination coverage data at 30/06/2013. [in Italian]. Available at: http://www.epicentro.iss.it/problemi/hpv/pdf/HPV_30-06-2013.pdf Accessed 10 March 2014.

7. ICONA Working Group: ICONA 2008: national vaccination coverage survey among children and adolescents. 2009, viii, 118 p. Rapporti ISTISAN 09/29. [in Italian] Istituto Superiore di Sanità, Roma. Available at: http://www.iss.it/ binary/publ/cont/09_29_web.pdf Accessed 10 March 2014.

8. Kessels SJ, Marshall HS, Watson M, Braunack-Mayer AJ, Reuzel R, Tooher RL: Factors associated with HPV vaccine uptake in teenage girls: a systematic review. Vaccine 2012, 30(24):3546-56.

9. Hopkins TG, Wood N: Female human papillomavirus (HPV) vaccination: global uptake and the impact of attitudes. Vaccine 2013, 31(13):1673-9.

10. Trim K, Nagji N, Elit L, Roy K: Parental knowledge, attitudes, and behaviours towards human papillomavirus vaccination for their children: a systematic review from 2001 to 2011. Obstet Gynecol Int 2012, 2012:921236.

11. Hanley SJ, Yoshioka E, Ito Y, Konno R, Hayashi Y, Kishi R, Sakuragi N: Acceptance of and attitudes towards human papillomavirus vaccination in Japanese mothers of adolescent girls. Vaccine 2012, 30(39):5740-7.

12. Haesebaert J, Lutringer-Magnin D, Kalecinski J, Barone G, Jacquard AC Regnier V, Leocmach Y, Vanhems P, Chauvin F, Lasset C: French women's knowledge of and attitudes towards cervical cancer prevention and the acceptability of HPV vaccination among those with 14-18 year old daughters: a quantitative-qualitative study. BMC Public Health 2012, 12:1034.

13. Betsch C, Sachse K: Debunking vaccination myths: strong risk negations can increase perceived vaccination risks. Health Psychol 2013, 32(2):146-55.

14. Censis: Italian women and HPV prevention. In Knowledge on Human papillomavirus diseases and attitude to vaccination. Rome; 2011. [in Italian] Available at: http://www.censis.it/7? shadow_comunicato_stampa=113915 Accessed 30 June 2014.

15. Donati S, Giambi C, Declich S, Salmaso S, Filia A, Atti ML C d, Alibrandi MP, Brezzi S, Carozzi F, Collina N, Franchi D, Lattanzi A, Meda M, Minna MC, Nannini R, Gallicchio G, Bella A, PreGio Working group: Knowledge, attitude and practice in primary and secondary cervical cancer prevention among young adult Italian women. Vaccine 2012, 30(12):2075-82.
16. Sopracordevole F, Cigolot F, Mancioli F, Agarossi A, Boselli F, Ciavattini A: Knowledge of HPV infection and vaccination among vaccinated and unvaccinated teenaged girls. Int J Gynecol Obst 2013, 122:48-51.

17. Gefenaite G, Smit M, Nijman HW, Tami A, Drijfhout IH, Pascal A, Postma MJ Wolters BA, van Delden JJ, Wilschut JC, Hak E: Comparatively low attendance during Human Papillomavirus catch-up vaccination among teenage girls in the Netherlands: Insights from a behavioral survey among parents. BMC Public Health 2012, 12:498.

18. Di Giuseppe G, Abbate R, Liguori G, Albano L, Angelillo IF: Human papillomavirus and vaccination: knowledge, attitudes, and behavioural intention in adolescents and young women in Italy. Br J Cancer 2008, 99(2):225-9.

19. Dorell C, Yankey D, Strasser S: Parent-reported reasons for nonreceipt of recommended adolescent vaccinations, national immunization survey: teen, 2009. Clin Pediatr (Phila) 2011, 50(12):1116-24.

20. Bartlett JA, Peterson JA: The uptake of Human Papillomavirus (HPV) vaccine among adolescent females in the United States: a review of the literature. J Sch Nurs 2011, 27(6):434-46.

21. Zimmerman RK, Wolfe RM, Fox DE, Fox JR, Nowalk MP, Troy JA, Sharp LK: Vaccine criticism on the World Wide Web. J Med Internet Res 2005, 7(2):e17.

22. Poscia A, Santoro A, Collamati A, Giannetti G, De Belvis AG, Ricciardi W, Moscato $U$ : Availability and quality of vaccines information on the Web: a systematic review and implication in Public Health. Ann lg 2012, 24(2):113-21.

23. La Torre G, De Vito E, Ficarra MG, Firenze A, Gregorio P, Boccia A, HPV Collaborative Group: Is there a lack of information on HPV vaccination given by health professionals to young women? Vaccine 2013, 31:4710-13.

doi:10.1186/s12879-014-0545-9

Cite this article as: Giambi et al:: Exploring reasons for non-vaccination against human papillomavirus in Italy. BMC Infectious Diseases 2014 14:545.

\section{Submit your next manuscript to BioMed Central and take full advantage of:}

- Convenient online submission

- Thorough peer review

- No space constraints or color figure charges

- Immediate publication on acceptance

- Inclusion in PubMed, CAS, Scopus and Google Scholar

- Research which is freely available for redistribution 